\title{
The Imilchil meteorite strewn field and Isli-Agoudal craters
}

\author{
Hassane Nachit ${ }^{1}$, Abderrahmane Ibhi $^{1}$, Carmela Vaccaro ${ }^{2}$ \\ ${ }^{1}$ Geoheritage and Geomaterials Laboratory, Faculty of Sciences, University of Ibn Zohr, B.P. 8106, \\ Agadir, Morocco. \\ ${ }^{2}$ Department of Earth Sciences, University of Ferrara, P1-SZA103 Via Saragat, 1, \\ Ferrara - 44100, Italy. \\ E-mail address: h.nachit@uiz.ac.ma
}

\begin{abstract}
New meteorite prospections at different places in the region of Imilchil showed that (1) besides the Ataxite of Tasraft all the other collected specimens belong to the same and only IIAB iron mother meteorite (2) the strewn field of the meteorite has a length of about $38 \mathrm{~km}$ into north-south direction (3) the small crater of Agoudal as well as the impact crater of Isli are situated on a parallel north-south axis, if not put together with the strewn field of the Imilchil meteorite (4) these two structures might be the result of the fall of the same and only mother meteorite of the IIAB type.
\end{abstract}

Keywords: Meteorite; Strewn field; Isli; Agoudal; Impact crater; Morocco

\section{INTRODUCTION}

Our study had been carried out in the axial zone of the central Moroccan High Atlas. This zone constitutes of sedimentary deposits with an age range beginning at the Trias and ending at the middle Cretaceous. These terrains were structured in the course of the alpine orogeny in an alternation of anticlinal mega-structures along the direction $\mathrm{N} 70^{\circ} \mathrm{E}$ and broad flat synclinal mega-structures along the same direction.

The work of Ibhi et al. (2013) [1] showed, that the lake Isli $\left(32^{\circ} 13 \mathrm{~N}, 05^{\circ} 38^{\prime} \mathrm{W}\right)$ is the result of a meteorite fall 40.000 years ago. In the location of Agoudal at $20 \mathrm{~km}$ to the south of lake Isli Sadilenko et al. (2013) [2] mentioned the presence of a small impact crater of an age of 10.000 years situated at (31 $\left.{ }^{\circ} 59^{\prime} 12.7^{\prime \prime} \mathrm{N}, 5^{\circ} 30^{\prime} 57,3^{\prime \prime} \mathrm{W}\right)$. These two structures are situated on a north-south axis (Fig. 1.) New meteorite prospection performed in collaboration with professional prospectors and merchants at various locations nearby Imilchil (Agoudal, Akdim, Bouzmou, Tighdouine, etc.) allowed us to determine the direction and the length of the strewn field. We want to show in this paper, that the two impact craters cited above, might be the result of the fall of one and the same mother meteorite of type IIAB about 40.000 years ago and that the strewn field of the Imilchil meteorite has a length of about $38 \mathrm{~km}$ with a northsouth direction. 


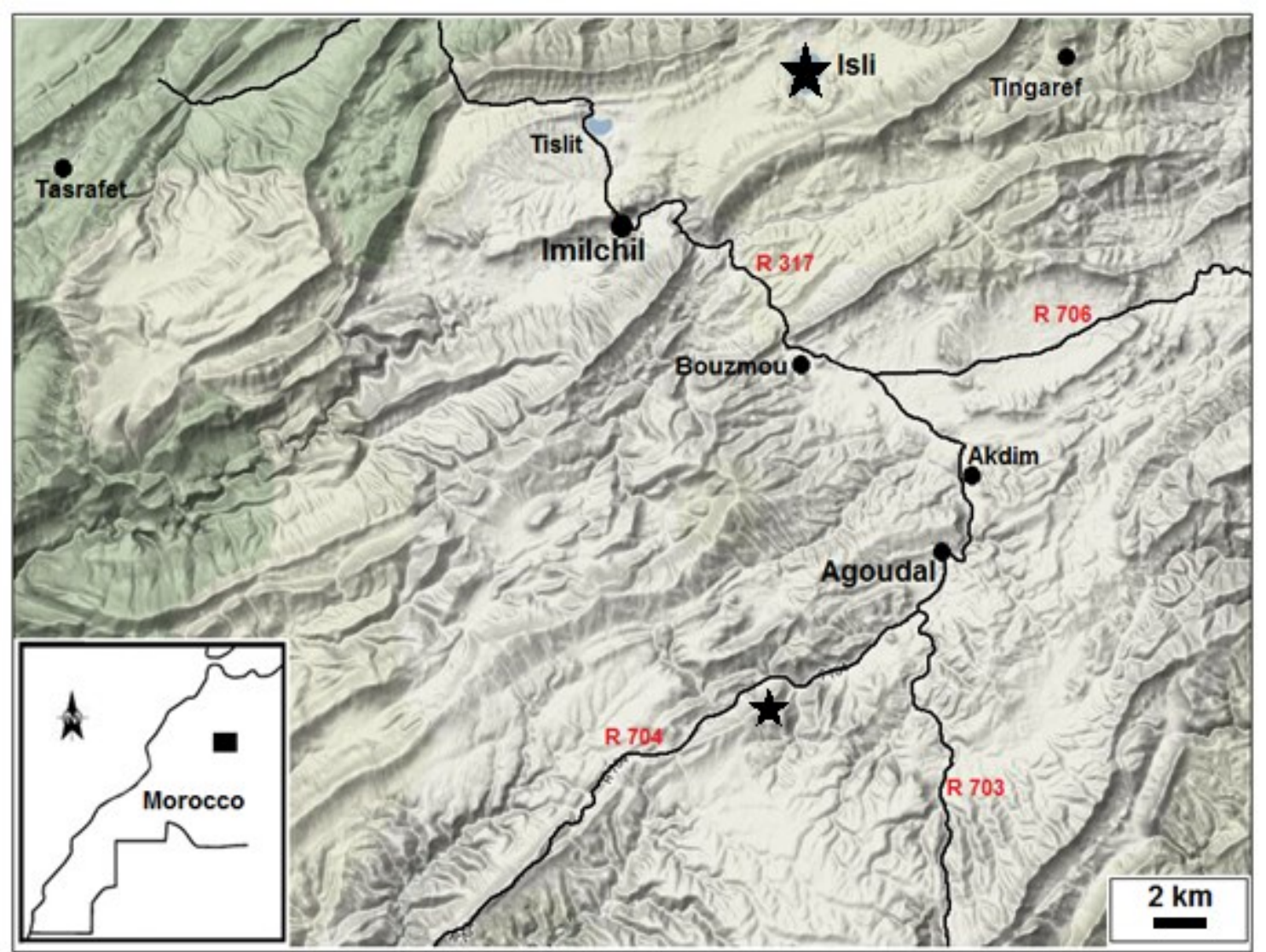

Fig. 1. Topographic map showing the location of Isli and Agoudal craters (stars).

\section{IMPACT CRATERS}

\section{1. Isli}

The crater Isli [1] is an almost regular bowl with very pronounced slopes. Its maximum depth is 95 meters and the measured seismic profiles revealed that the thickness of sediments filling the lake is about 100 meters, where the oldest ones have an age of about 40000 years [3] (Zeroual, 1995). The sedimentary formations that are almost tabular at the platform of the lake become inclined with centripetal dips, all around towards the lake Isli forming thus its watershed.

Polymict and monomict breccias were observed at the edges of these craters. They don't form big masses, the erosion has probably erased most of them. They consist of irregular fragments with millimeter and centimeter sizes in a carbonate matrix.

In the breccias collected on the southern edges of the Isli crater we noted the presence of several shocked quartz grains with planar structures (PF) [4,5] associated sometimes with rolling extinction, which are indicators of shock metamorphism.

Most quartz grains have a single family of PFs (Fig. 2), but some grains have two families of planar structures. These breccias could be the result of the ejected debris. We also had been able to observe radial fractures which could have been produced by impacts [6]. 

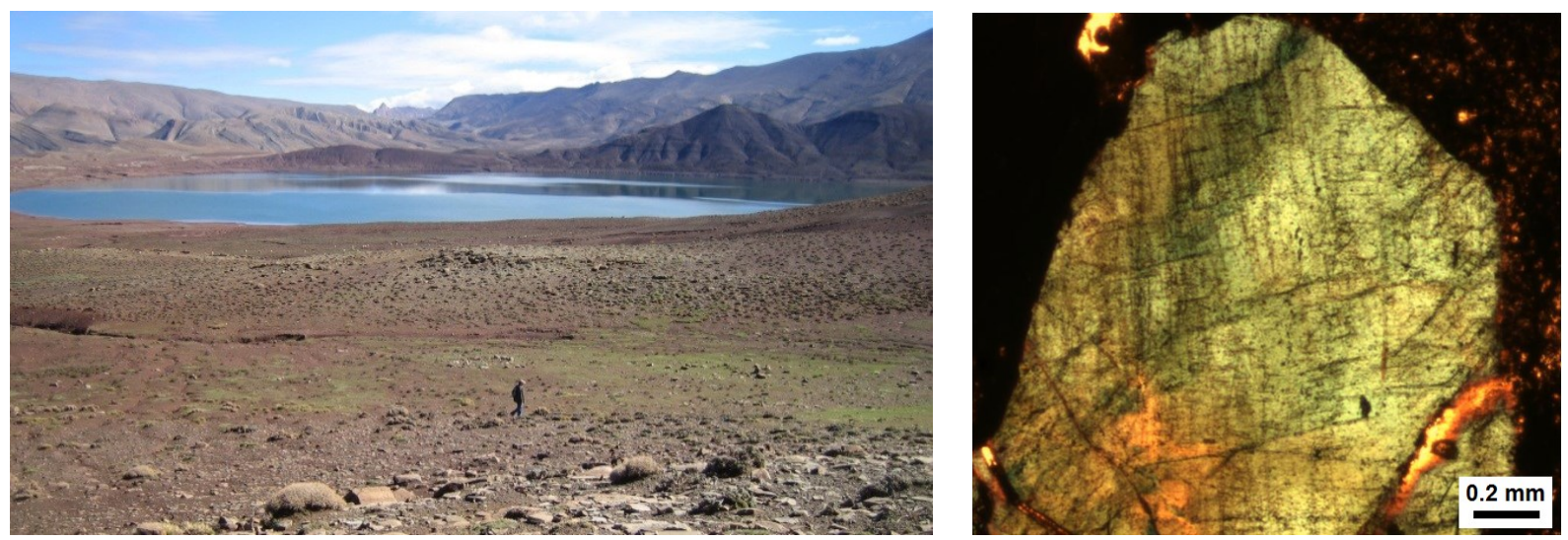

Fig. 2. Isli crater and shocked quartz showing PFs.

\section{2. Agoudal}

A small eroded impact crater was recognized at about $25 \mathrm{~km}$ to the south of lake Isli at $\left(31^{\circ} 59^{\prime} 12.7^{\prime \prime} \mathrm{N} ; 5^{\circ} 30^{\prime} 57.3^{\prime \prime} \mathrm{W}\right)$. The crater had been recognized through the presence of shatter cones [2].

Our mission on the terrain showed us, that the location of the crater corresponds to the flank of a syncline with a dip of $25^{\circ}$ to the north. Its shape cannot be defined because of a lack of a visible rim or something else which would distinguish it from the surrounding facies. Additionally, the whole north-western part of the synclinal flank, where the crater is located, is washed out by a big valley with a width of $300 \mathrm{~m}$. However very beautiful shatter cones (Fig. 3) have been found in samples of Jurassic limestone wrapped in quaternary deposits, predominantly at the flanks of the dry rivers which cut the syncline.
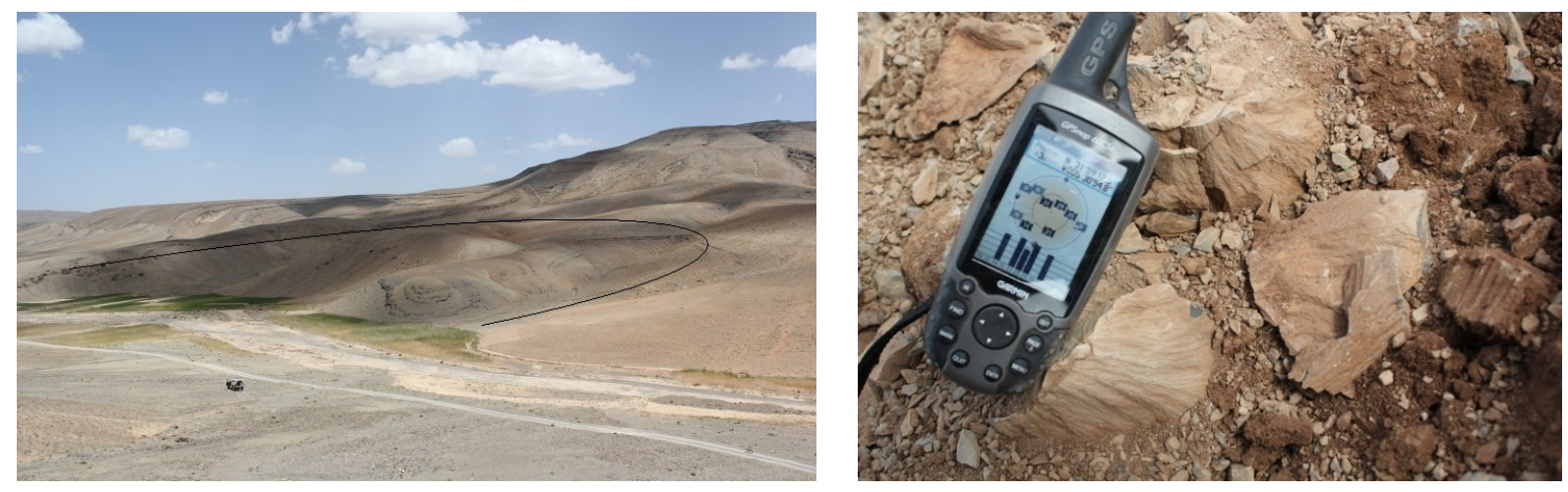

Fig. 3. Agoudal crater and shatter cones.

\section{METEORITE}

The members of the laboratory collected many fragments of Imilchil meteorite at the GPS coordinates Agoudal (31 $\left.59^{\prime} 08.0^{\prime \prime} \mathrm{N} ; \quad 05^{\circ} 31^{\prime} 00.6^{\prime \prime} \mathrm{W}\right), \quad \operatorname{Akdim} \quad\left(32^{\circ} 04^{\prime} 00.5^{\prime} \mathrm{N}\right.$; 


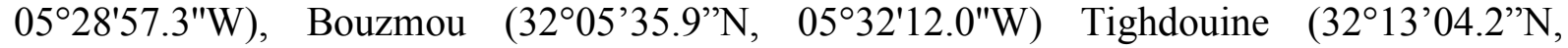
$\left.05^{\circ} 26^{\prime} 42.3^{\prime \prime} \mathrm{W}\right)$ and Tasrafet (32 $\left.{ }^{\circ} 10^{\prime} 56.4^{\prime \prime} \mathrm{N}, 05^{\circ} 52^{\prime} 59.5^{\prime \prime} \mathrm{W}\right)$ in Fig. 4.

Some of the found samples have a rusty appearance with a scale of alteration of several centimeters and thick layers of oxides and iron hydroxide covering the entire outer surfaces and indicating a long residence time in the soil. High humidity that occurred during the moist climate that prevailed in Africa during the ice ages has caused the major part of the corrosion to the meteorites.

Besides the meteorite found nearby Tasraft, a small village situated at about $30 \mathrm{~km}$ to the west of lake Isli (Fig. 1), all the other specimens collected at different places in the region of Imilchil had the same chemical composition and even the same mineralogical characteristics of a IIAB iron meteorite. Indeed bulk chemical analyses of samples by Herd and Chen [7] and Vaccaro (University of Ferrara, Italy) revealed an average composition of 6wt. \% Ni, $4 \mathrm{mg} / \mathrm{g} \mathrm{Co}, 60 \mu \mathrm{g} / \mathrm{g}$ Ga and $<0.05 \mu \mathrm{g} / \mathrm{g}$ Ir.

The scanning electron-microscopy revealed a coarse pattern of irregular interlocking kamacite grains thereunder some grains with sub-boundaries. The samples don't show the Widmanstätten figures and schreibersites, $(\mathrm{Fe}, \mathrm{Ni}) 3 \mathrm{P}$, occur abundantly as mm-sized skeletal crystals at the centers of kamacite crystals. These schreibersites often exhibit embayments or skeletal morphologies. It is well-known that schreibersite textures are the result of high-speed collisions occurring in the asteroid belt [8]. Its chemical composition (X-ray fluorescence) is: 63.79 wt \% Fe, $21.42 \mathrm{wt} \% \mathrm{Ni}$ and $14.79 \mathrm{wt} \% \mathrm{P}$.

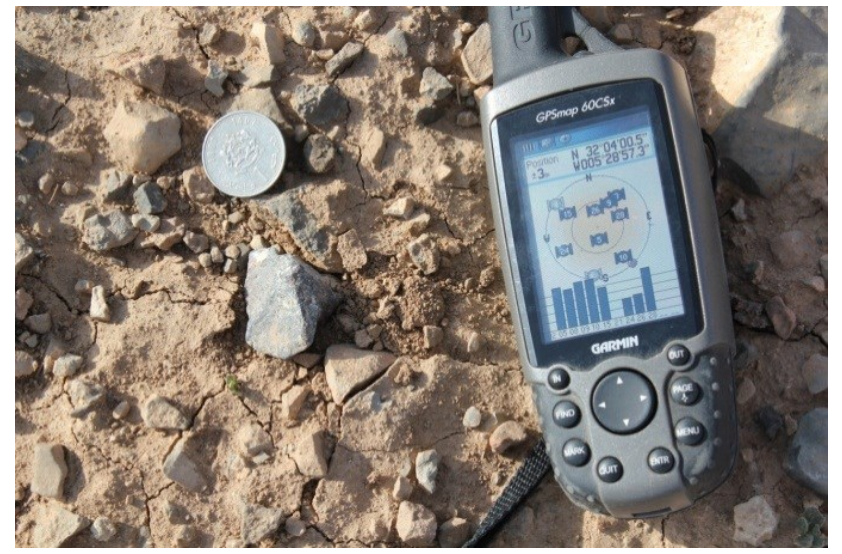

Sample of Akdim (45 grams)

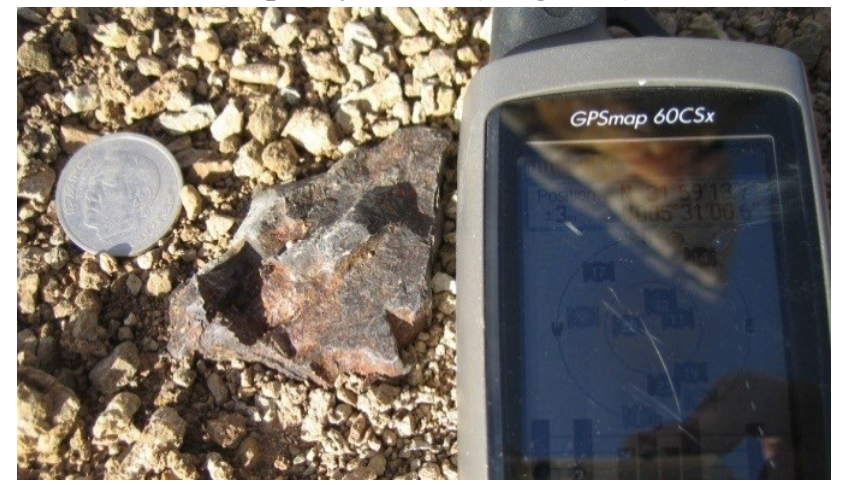

Sample of Agouda north (265 grams)

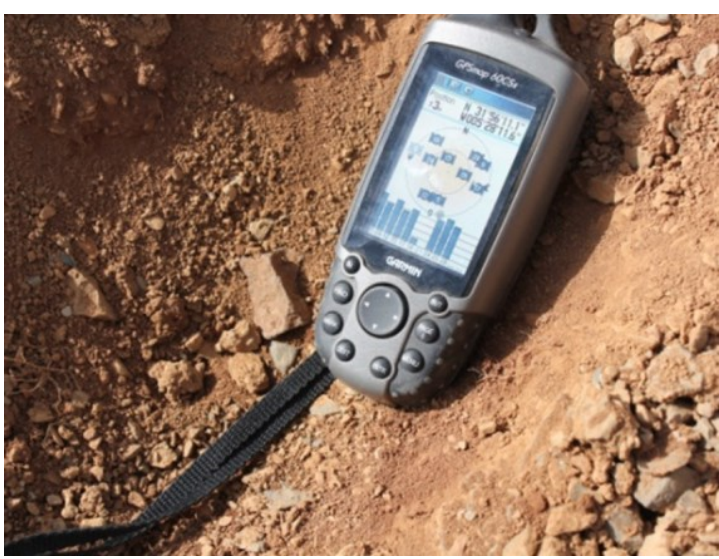

Sample of radar, south of Agoudal (29 grams)

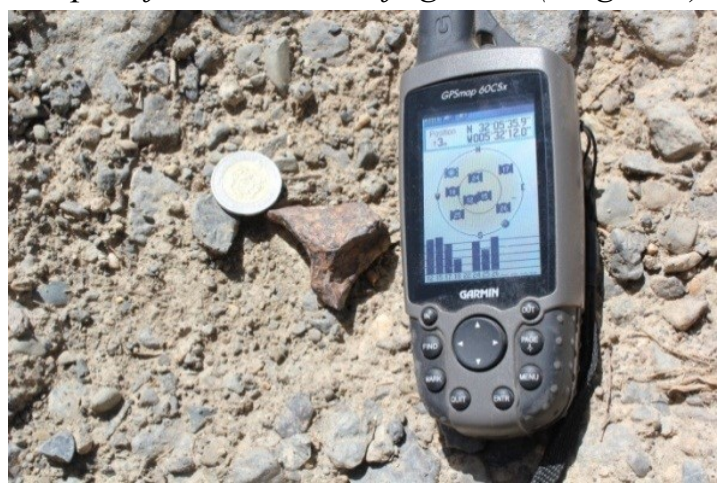

Sample of Bouzmou (65 grams)

Fig. 4. Imilchil meteorite fragments. 


\section{STREWN FIELD}

The first fragment of the Imilchil meteorite was collected by a nomad in 2007. In 2012 many pieces of this meteorite came into the Laboratory of the Ibn Zohr University. Immediately a systematic search for meteorites was conducted in collaboration with professional prospectors and merchants to define the direction of strewn field.

The mapping of the locations, where the fragments of the meteorite were found, showed us that the fireball exploded into thousands of fragments that are scattered on a field with a north-south direction and about $38 \mathrm{~km}$ long (Fig. 5), which would be the direction of the strewn field. The width of the ellipsoid is not yet well defined by the lack of data, especially in the very steep northern part, where the specimens were found by chance and picked up by shepherds. North of lake Isli the meteorite occurs only in small millimeter- to centimetersized fragments included in breccias or in small veins of silicate liquid.

The Agoudal area at the south, where the maximum of the samples were collected, is a desert area, relatively flat and was dotted with hundreds of meteorites that were collected since 2007. More than a ton of specimens were collected over a period of 6 years. Some sources speculate that even a still bigger quantity had been recovered (up to 2 tons) but there is no way to make an accurate estimate. Due to the continuing intense exploration specimens are still found. The fragments weight from 1 gram to $196 \mathrm{~kg}$.

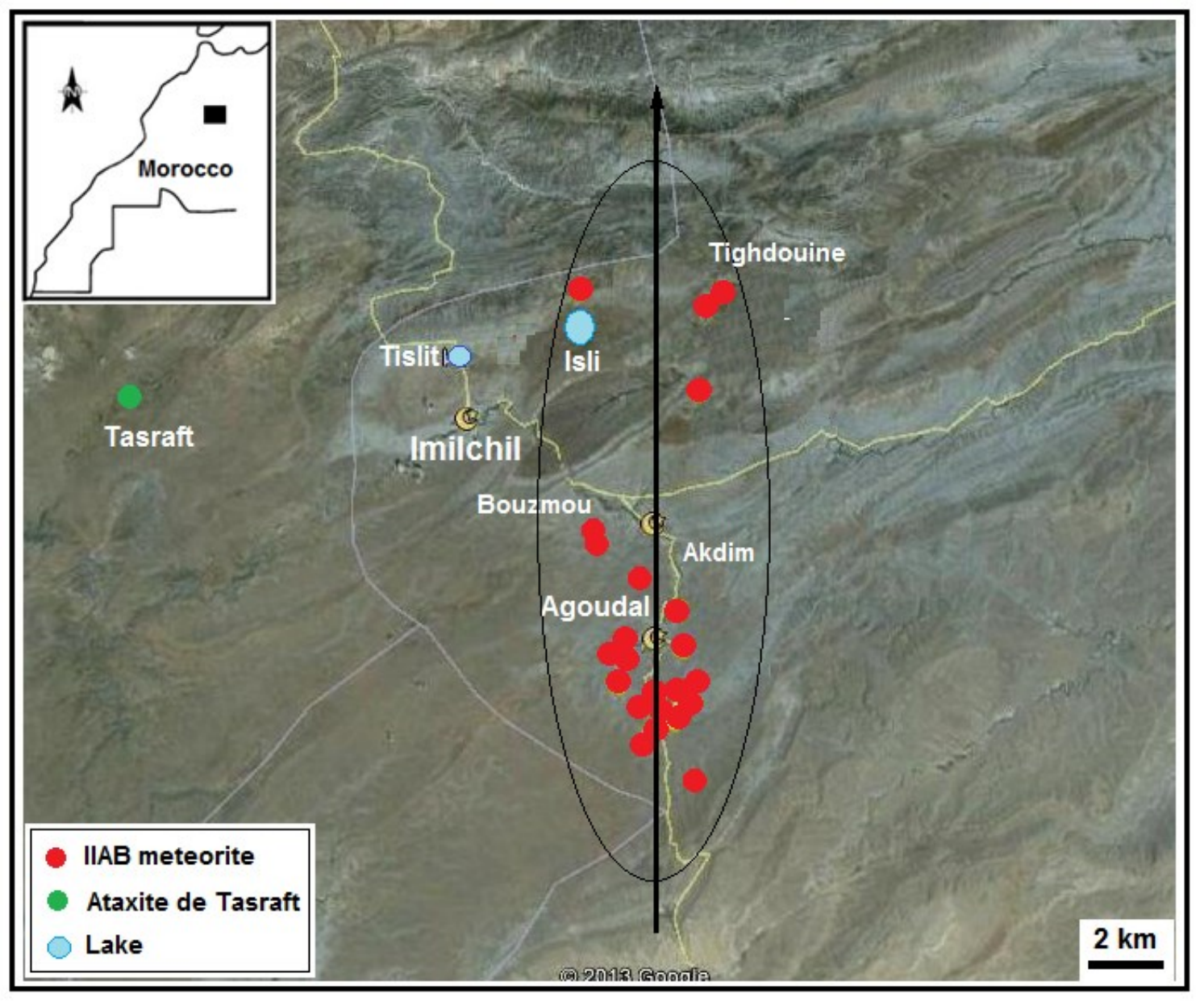

Fig. 5. The Imilchil meteorite strewn field. 


\section{DISCUSSION AND CONCLUSION}

With the exception of the Ataxite collected at Tasraft situated at the west of lake Isli, the fragments found at various locations in the region of Imilchil showed the same chemical composition and the same mineralogical characteristics of a IIAB iron meteorite. In other words, besides the Ataxite of Tasraft all the meteorite fragments collected in the region of Imilchil belong to one and the same mother iron meteorite of IIAB type.

Fragments from $1 \mathrm{~g}$ to $196 \mathrm{~kg}$ had been collected or observed at a distance of $38 \mathrm{~km}$ from the south of Agoudal to about the lake Isli in the north, which shows the force of the explosion of the meteorite or simply the direction of the strewnfield. Hence it is reasonable to name every specimen, which is part of this strewnfield as a fragment of the Imilchil meteorite.

The small crater of Agoudal [2] as well as the impact crater of Isli [1] are situated on a parallel north-south axis, if not put together with the strewn field of the Imilchil meteorite. Form these observations we can affirm that these two structures have been produced by the impact of a small asteroid with a diameter of more than $100 \mathrm{~m}$. The double impact crater follows of a breakup of a meteorite into two pieces at its entry in the earth's atmosphere, which then produced the two craters in the orientation of the trajectory of the bolide $[9,10]$.

This phenomena has been observed for the three documented double craters of the world [11]. The presence of meteorite specimens in the Soltanian sediments [1] indicates that the fall of the meteorite must have taken place about 40.000 years ago [12]. This age is consistent with the age of the oldest sediments of lake Isli, which had been dated to an age of 35.000 years [3].

\section{Acknowledgments}

We want to thank Bassou moulay Ali, Assou Baadich, Ainouch Mohamed and Outouch moha for their assistance in the collection of information. I also, we want to thank Professor Abia El Hassan and Ait Touchnt for help and discussions. In addition, the manuscript has also been improved by corrections on the English by Diplomphysiker Klaus Schneider.

\section{References}

[1] Ibhi A., Nachit H., Abia E., Ait Touchnt A., Vaccaro C., International Journal of Astronomy and Astrophysics 3 2A (2013) 1-4, doi: 10.4236/ijaa.2013.32A001.

[2] Sadilenko D. A., Lorenz C. A., Ivanova M. A., Roshina I. A., Korochantsev A. V., 76th Annual Meteoritical Society Meeting, July 29-August 2, 2013, Edmonton, Alberta, Canada, Abstract No. 5215.

[3] Zeroual E., Ph.D. Thesis, 1995, Cadi Ayad University, Morocco 230 pages.

[4] Stöeffler D., Langenhorst F., Meteoritics and Planetary Science 29 (1994) 155-181.

[5] Grieve R. A. F., Langenhorst F., Stöffler D., Meteoritics and Planetary Science 31 (1996) 6-35.

[6] Sagy A., Reches Z., Fineberg J., Nature 418 (2002) 310-313. 
[7] Herd C., Chen G., Published in Meteoritical Bulletin 102, MAPS 48, in preparation (2014).

[8] Britvin S. N., Rudashevsky N. S., Krivovichev S. V., Burns P. C., Polekhovsky Y. S., American Mineralogist 87 (2002) 1245-1249.

[9] Dence M. R., Nature 289(198) (1981) 346-351.

[10] French B. M., Koeberl C., Earth-Science Reviews 98 (2010) 123-170.

[11] Salomon J. N., Auly T., Géomorphologie (2010) 3-20. ISBN 2-913282-47-4.

[12] Weisrock A., Fontugne M., Quaternaire 3 (1991) 164-175. 